\title{
Liposoluble portion of the red alga Pyropia yezoensis protects alcohol induced liver injury in mice
}

\author{
Ji-Hyeok Lee ${ }^{1,2,3}$, Ginne Ahn" ${ }^{4}$ Ju-Young Ko ${ }^{5,6}$, Nalae Kang ${ }^{4}$, Kyungsook Jung ${ }^{7}$, Eui-Jeong \\ $\mathrm{Han}^{4}$, Gwang-Hoon Kim ${ }^{8}$, Hee Jeong Kim ${ }^{2}$, Cheol Soo Choi ${ }^{3,9}$ and You-Jin Jeon ${ }^{5, *}$ \\ ${ }^{1}$ Natural Products Research Division, Honam National Institute of Biological Resources, Mokpo 58762, Korea \\ ${ }^{2}$ Jeju Institute of Korean Medicine, Jeju 63309, Korea \\ ${ }^{3}$ Korea Mouse Metabolic Phenotyping Center, Lee Gil Ya Cancer and Diabetes Institute, Gachon University, Incheon 21999, \\ Korea \\ ${ }^{4}$ Department of Marine Bio-Food Sciences, Chonnam National University, Yeosu 59626, Korea \\ ${ }^{5}$ Department of Marine Life science, Jeju National University, Jeju 63243, Korea \\ ${ }^{6}$ Research Institute of Basic Sciences, Incheon National University, Incheon 22012, Korea \\ ${ }^{7}$ Immunoregulatory Materials Research Center, Korea Research Institute of Bioscience and Biotechnology (KRIBB), \\ Jeongeup 56212, Korea \\ ${ }^{8}$ Department of Biology, College of Natural Sciences, Kongju National University, Kongju 32588, Korea \\ ${ }^{9}$ Division of Endocrinology \& Metabolism, Department of Internal Medicine, Gil Medical Center, Gachon University \\ College of Medicine, Incheon 21565, Korea
}

The hepatoprotective effect of liposoluble portion of Pyropia yezoensis (PYLP) was investigated against alcohol-induced liver injury in mice. Fatty acids were predominant in PYLP obtained from hexane fraction of $70 \%$ EtOH extract after ultrasonication. In particular, polyunsaturated fatty acids such as eicosapentaenoic acid and linoleic acid accounted for $56.91 \%$ of the total lipids. PYLP significantly reduced liver damage induced by the alcohol treatment in mice. PYLP treatment increased the activity of antioxidant enzymes including superoxide dismutase, catalase, and glutathion peroxidase by reducing thiobarbituric acid reactive substances. Histological observations showed that PYLP minimizes damage to living tissue induced by alcohol treatment by modulating the expression level of proteins involved in the anti-apoptotic signaling pathway. Our results suggest that PYLP, rich in polyunsaturated fatty acids extracted from the red alga P. yezoensis, will be useful as a potential liver protectant in the hangover industry.

Key Words: alcohol damage; hepatic protective effect; liposoluble portion; marine red alga; polyunsaturated fatty acids; Pyropia yezoensis

\section{INTRODUCTION}

Liver disorders are caused by various agents such as alcohol, environmental toxins and viruses, and they remain one of the major threats to public health (Suresh and Asha 2008). Alcohol abuse has widespread negative impacts on human health and social economy. Chronic exposure to alcohol causes significant damages to the liver and can result in microvascular steatosis, apoptosis, necrosis, inflammation, hepatic fibrosis, and ultimately,

\section{(ब) (1) $(9$}

This is an Open Access article distributed under the terms of the Creative Commons Attribution Non-Commercial License (http://creativecommons.org/licenses/by-nc/3.0/) which permits unrestricted non-commercial use, distribution, and reproduction in any medium, provided the original work is properly cited.
Received December 23, 2020, Accepted April 28, 2021

* Corresponding Author

E-mail: youjin2014@gmail.com

Tel: +82-64-754-3475, Fax: +82-64-756-3493 
cirrhosis (Lambert et al. 2003, Lu et al. 2015). Therefore, there are ongoing researches on potential pharmacotherapeutic agents to cure alcoholic hepatitis. Previously reported therapeutic agents for alcoholic hepatitis, such as pentoxifylline, infliximab, and etanercept are associated with side effects including an increase in infections and death (Santos Rocha et al. 2012). Undoubtedly, natural products could be alternatives to synthetic medicines for the prevention of alcohol-induced disorders (Lin et al. 2014).

Marine algae are rich in functional ingredients such as polysaccharides, polyphenols, phytosterols, and carotenoids (Lee et al. 2013, 2014, 2020, Kim et al. 2014, 2016, Shanura Fernando et al. 2017, Asanka Sanjeewa et al. 2019, Ding et al. 2019, Dai et al. 2020). Pyropia species, belonged to Bangiaceae family which are the most important perennial edible marine red algae, are cultivated and consumed in East and Southeast Asian countries such as Korea, Japan, and China. P. yezoensis is well known for its nutritional value. It has been used as a food source and a traditional medicine material for centuries in Asia (Kazłowska et al. 2013). Because it is rich in biological components such as sterols, dietary fibers, taurine, polyunsaturated fatty acids, carotenoids, and mycosporine-like amino acids including porphyra-334. It is also rich in minerals, vitamins, and proteins (Isaka et al. 2015, Zang et al. 2020). Porphyran, a water soluble portion, is a functional sulfated polysaccharide obtained from $P$. yezoensis and has shown strong protective effects in mice against carbon tetrachloride $\left(\mathrm{CCl}_{4}\right)$-induced hepatotoxicity, caused by inflammatory reactions, free radicals, and lipid peroxidation (Guo et al. 2007). However, the hepatoprotective effect of a liposoluble portion in P. yezoensis (PYLP) has not been reported. In this study, therefore, the in vivo protective effect of PYLP against the alcohol-damaged liver was studied.

\section{MATERIALS AND METHODS}

\section{Reagents}

All solvents used for sample preparation were of analytical grade (Daejung Chemicals \& Metals Co., Seoul, Korea). High-performance liquid chromatography (HPLC) grade solvents were purchased from Burdick \& Jackson (Muskegan, MI, USA). Arylesterase / Paraoxonase assay kit was purchased from ZeptoMetrix Corporation (Stamar, Dabrowa Gornicza, Poland). Antibodies against p53, Bcl-xL, Bax, and $\beta$-actin were purchased from Cell
Signaling Technology (Bedford, MA, USA). All other chemicals and reagents were used as analytical grade.

\section{Collect of Pyropia yezoensis}

P. yezoensis was collected at near coast of Wondo on November 2014 and inspected by comparing with specimen (No. 131) supported by Dr. Lee, Ki-Wan retired from Jeju National University, then P. yezoensis was washed three times by tap water to the derived foreign matters which dried by freeze dryer (PVTFD 10A; Ilshin Bio Base Co., Ltd., Dongducheon, Korea), kept at $-4^{\circ} \mathrm{C}$ until its usage.

\section{Preparation of polyunsaturated fatty acids-rich PYLP}

In order to prepare PYLP, firstly, a 70\% ethanol extract (85 g) was manufactured by three times extracting from dried P. yezoensis ( $600 \mathrm{~g}$ ) in ultrasonication. And the dried extract powder was prepared through steps by a rotary evaporator (N-1000; Tokyo Rikikai Co., Ltd., Tokyo, Japan) and freeze dryer (SFDSM06; Samwon Freezing Exgineering Co., Busan, Korea), respectively. Finally, PYLP (12.56 g) was obtained from suspension fraction using n-hexane and distilled water $(1: 1, \mathrm{v} / \mathrm{v})$, and then kept in refrigerator $\left(\right.$ at $\left.-20^{\circ} \mathrm{C}\right)$ after drying.

\section{Analysis of biological components in PYLP}

Fatty acids. PYLP was dissolved in n-hexane and 0.2 $\mathrm{mL}$ of $2 \mathrm{M}$ methanolic- $\mathrm{NaOH}$ was added. Then, the mixture was shaken and kept at $50^{\circ} \mathrm{C}$ for $30 \mathrm{~s}$, and then 0.2 $\mathrm{mL}$ of $2 \mathrm{M} \mathrm{HCl}$ in methanol was added and shaken to neutralize. The mixture was separated by centrifugation at $700 \times \mathrm{g}$ for $5 \mathrm{~min}$, the upper $\mathrm{n}$-hexane layer was collected and concentrated. A 0.5 m thickness PEG-20 M liquid phase-coated $40 \mathrm{~m} \times 1.2 \mathrm{~mm}$ diameter G-300 column (Chemicals Evaluation and Research Institute, Saitama, Japan) was used for analysis by connecting it to a Hitachi 263 gas chromatograph (Hitachi Co., Ltd., Ibaraki, Japan) equipped with a flame ionization detector. The temperatures of the column, detector, and injection port were set to 190,240 , and $250^{\circ} \mathrm{C}$, respectively.

Total sterols. The conditions used for saponification and extraction are modified from those proposed by Sánchez-Machado et al. (2004). PYLP $(1.00 \pm 0.01 \mathrm{~g})$ was weighed out in an Erlenmeyer flask and saponified by refluxing with $27 \mathrm{~mL}$ of $1 \mathrm{M}$ ethanolic $\mathrm{KOH}$ for $30 \mathrm{~min}$ with a constant shaking under the temperature of $80^{\circ} \mathrm{C}$. After 
cooling to ambient temperature, the mixture was transferred to a separation funnel to extract the non-saponifiable fraction with total $40 \mathrm{~mL}$ including $20 \mathrm{~mL}$ of DW + the mixture and $20 \mathrm{~mL}$ of hexane (agitation washing for 3 min each time). The hexane containing the sterols was evaporated to dryness in a rotavapor at $40^{\circ} \mathrm{C}$. The quantification of total sterol was evaluated by Livermann-burchard test. The residue was dissolved in $3 \mathrm{~mL}$ of mobile phase (30:70, methanol : acetonitrile, $\mathrm{v} / \mathrm{v})$, then filtered through a $0.45 \mu \mathrm{m}$ membrane. A $10 \mu \mathrm{L}$ of this extract was injected into the HPLC column (Waters Corporation, Milford, MA, USA). The HPLC-UV system comprised a liquid chromatograph equipped with a 515 HPLC pump, and a photo diode array detector (2998 PDA detector), controlled by Empower software (Waters Corporation). Temperature was controlled at $50 \pm 0.1^{\circ} \mathrm{C}$ with a column heater (Waters Corporation). Separation was performed in a SunFire C18 $5 \mu \mathrm{m}$ column $(4.6 \times 250 \mathrm{~mm}$ i.d.; Waters Corporation), with $30: 70$ (methanol: acetonitrile, $v / v$ ) at $1.0 \mathrm{~mL} \mathrm{~min}^{-1}$ as a mobile phase. The eluted solution was detected at $200 \mathrm{~nm}$ wavelength. Each sterol from PYLP was identified by the report of Sánchez-Machado et al. (2004).

$\boldsymbol{\beta}$-Carotene. The analysis for quantification of $\beta$-carotene is modified from those proposed by Ahamad et al. (2007). Standard of $\beta$-carotene (1 g enclosed in vial) was purchased from Merck KGaA (Darmstadt, Germany). Stock solution of $\beta$-carotene was prepared by taking 10 $\mathrm{mg}$ in $100 \mathrm{~mL}$-hexane. The concentration of stock solution was equal to $100 \mathrm{ppm}$. HPLC system and chromatographic condition was Perkin Elmer HPLC programme containing LC-1000 pump (Isocratic), equipped with C18 column and LC 250 UV/VIS detector (PerkinElmer Inc., Waltham, MA, USA). HPLC was calibrated by running mobile phase (acetonitrile : dichloromethane : methanol, $70: 20: 10$ ) at the rate of $1 \mathrm{~mL} \mathrm{~min}^{-1}$. The wave length was fixed at $452 \mathrm{~nm}$. A $10 \mu \mathrm{L}$ of $\beta$-carotene or PYLP was injected into the HPLC column. The concentration of the $\beta$-carotene in PYLP was calculated using the $\beta$-carotene standard curve.

\section{Animal and experimental design}

Male BALB/c mice (6-week-old, 23-26 g body weight) were purchased from Dae Han Bio Link Co., Ltd. (Eumseong, Korea). All these mice raised in the specific pathogen free clean room under conditions of 21 to $25^{\circ} \mathrm{C}$ and a $12 \mathrm{~h}$ dark : light cycle, and had free access to laboratory chow and tap water. Jeju National University's Institutional Animal Care and Use Committee approved the protocol for the animal study, and the animals were cared for in accordance with the "Guidelines for Animal Experiments" set by the university.

Balb/c mice were randomly divided into four groups as following: normal group (saline applied mice, each 100 $\mu \mathrm{L}, \mathrm{n}=6$ ), alcohol only (alcohol $3 \mathrm{~g} \mathrm{~kg}^{-1}$ mice and saline co-applied mice, each $100 \mu \mathrm{L}, \mathrm{n}=10$ ), PYLP + alcohol (alcohol $3 \mathrm{~g} \mathrm{~kg}^{-1}$ mice and PYLP $25 \mathrm{mg} \mathrm{kg}^{-1}$ mice co-applied mice, each $100 \mu \mathrm{L}, \mathrm{n}=10$ ), and silymarin + alcohol (alcohol $3 \mathrm{~g} \mathrm{~kg}^{-1}$ mice and silymarin $50 \mathrm{mg} \mathrm{kg}^{-1}$ mice co-applied mice, each $100 \mu \mathrm{L}, \mathrm{n}=6$ ). Alcohol, PYLP, and silymarin were daily oral administrated to mice using oral-zoned needle connected to a $1 \mathrm{~mL}$ syringe for 10 days. During the experiment period, the body weight and the survival rate of mice were daily measured. On the 10th day, the mice were dissected after the measurement of body weight. Additionally, blood samples were collected into heparin-coated tubes to determine biochemical parameters and liver tissues were stored at $-70^{\circ} \mathrm{C}$ until analysis.

\section{Detection of biochemical indicators in blood}

The serum activities of glutamic oxaloacetic transaminase (GOT) and glutamic pyruvic transaminase (GPT) were determined according to the Reitmen-Frankel method (Reitman and Frankel 1957) using an enzyme assay kit (Asan Pharmaceuticals, Hwasung, Korea). The total cholesterol content in the serum was determined using a commercial available kit (Asan Pharmaceuticals) according to the method of Allain et al. (1974). Also, lipid peroxidation concentrations in serum was determined by measuring thiobarbituric acid reactive substances (TBARS) based on the method of Ohkawa et al. (1979). The TBARS concentration was expressed as nmol of malondialdehyde (MDA) per mL serum.

\section{Measurement of the activities of antioxidant enzymes}

The liver tissue was homogenized by adding five volumes of ice-cold homogenization buffer $(250 \mathrm{mM}$ sucrose, 50 mM Tris-HCl, pH 7.4, 1 mM EDTA). After the homogenized liver tissue was centrifuged at $1,000 \times \mathrm{g}$ for 10 $\min$ and the supernatant was centrifuged again at 12,000 $\times \mathrm{g}$ for $30 \mathrm{~min}$. The final supernatant protein concentration was determined by the method of Bradford (1976) using bovine serum albumin as the protein standard. The activities of superoxide dismutase (SOD), catalase (CAT), and glutathione peroxidase (GPx) were measured using a commercially available kit (Biovision, Milpitas, CA, USA). 
The SOD activity was estimated spectrophotometrically at $450 \mathrm{~nm}$ while monitoring the inhibition of superoxide anions by the xanthine / xanthine oxidase system and the enzyme activity was expressed as $\mathrm{U} \mathrm{mg}^{-1}$ protein. The CAT activity was determined as the degradation rate of $\mathrm{H}_{2} \mathrm{O}_{2}$, and the degradation rate was measured at $570 \mathrm{~nm}$. In the GPx activity assay, enzymatic reactions involving $\mathrm{NADPH}$, reduced glutathione (GSH) and glutathione reductase, was initiated with the addition of cumene hydroperoxide. The change of absorbance was monitored at a wavelength of $340 \mathrm{~nm}$ and the activity was given as $\mathrm{mU} \mathrm{mg}^{-1}$ protein.

\section{Western blot test}

The liver tissue was homogenized in RIPA buffer (Sigma Chemical Co., St. Louis, MO, USA). After centrifugation at $12,000 \times \mathrm{g}$ for $10 \mathrm{~min}$, the protein concentration of the lysates was measured by BCA protein assay kit (Merck $\mathrm{KGaA}$ ). The lysates containing $50 \mu \mathrm{g}$ of protein were applied to $10-12 \%$ sodium dodecyl sulfate-polyacrylamide gel electrophoresis, and transferred to a nitrocellulose membrane. After blocking with a solution containing $5 \%$ skim milk in TBS containing $0.1 \%$ Tween 20 (TBS-T) for 2 $\mathrm{h}$ to prevent non-specific binding of antibody, the membranes were incubated with primary antibodies against Bax, p53, Bcl-xL, and $\beta$-actin in TBS-T for overnight at $4^{\circ} \mathrm{C}$. The membranes were then washed with TBS-T and incubated with secondary antibodies. Signals were developed using chemiluminescence Western blotting detection kit, and imaged on Davinch-Chemi imaging system (Core Bio, Seoul, Korea).

\section{Hematoxylin and eosin staining}

Liver tissues were fixed in $10 \%(\mathrm{v} / \mathrm{v})$ phosphate buffer formalin and embedded in paraffin wax. The paraffin sections (4-6 $\mu \mathrm{m}$ thick) were cut, and each section was stained with hematoxylin and eosin, and histological analysis was performed under light microscope (DP70; Olympus Optical Co., Tokyo, Japan).

Table 1. Comparison of the components contents in PYLP

\begin{tabular}{lc}
\hline Components & Contents (\%) \\
\hline Total lipids & $98.74 \pm 3.50$ \\
Total fatty acids & $84.52 \pm 0.30$ \\
$\beta$-carotene & $10.01 \pm 0.51$ \\
Total sterols & $2.30 \pm 0.20$ \\
\hline
\end{tabular}

Values are expressed as mean \pm standard error $(n=3)$. PYLP, liposoluble portion of Pyropia yezoensis.

\section{Statistical analysis}

All data were expressed as means \pm standard error and ANOVA was used to compare the means of two mice groups. Statistical significance at the $95 \%$ probability levels was set at $\mathrm{p}<0.05$.

\section{RESULTS AND DISCUSSION}

Alcoholic liver diseases remain a global health problem, but there are still no effective therapies. It is well established that oxidative stress induced by ethanol consumption plays a key role in the progression of liver damage. Therefore, the use of natural antioxidants is an effective approach to inhibit oxidative stress and alleviate ethanol-induced hepatotoxicity (Chen et al. 2016). For this reason, we investigated the water-insoluble extract of P.yezoensis, which contains abundant polyunsaturated fatty acids as a potential natural protector agent against hepatic injury induced by ethanol in mice.

PYLP was analyzed for various chemical components such as total fatty acids, $\beta$-carotene, and total sterols, and they indicated $84.52,10.01$, and $2.30 \%$, respectively (Table 1) to confirm target component for anti-alcoholic hepatic disease. As the result of fatty acid composition, PYLP contained several major fatty acids such as $54.12 \%$ eicosapentaenoic acid (EPA; C20:5), 21.07\% palmitic acid (C16:0), 6.43\% tricosanoic acid (C23:0), and 4.99\% linoleic acid (LA; C18:2) (Table 2). And the sterols were composed of $72.10 \%$ of desmosterol, $10.01 \%$ of cholesterol, and $17.31 \%$ of mixture of stigmasterol and campesterol (data not shown). Shin et al. (2013) and Parrish (2009) have reported that EPA is the dominant fatty acid in $P$. yezoensis, forming as much as $50 \%$ of the total fatty acid content. In our results also showed that PYLP contains high fatty acids content (84.52\%) and especially, exhibited $56.2 \%$ of polyunsaturated fatty acids. Also, this study showed high EPA content of $54.12 \%$.

Polyunsaturated fatty acids such as EPA and LA play a significant role in mitigating cardiovascular disease (Lemaitre et al. 2003, Yokoyama et al. 2007, Lluís et al. 2013), moderating tissue inflammation (Uauy and Valenzuela 2000, Ruxton et al. 2004), and contributing to the development of the nervous systems in humans (Burdge 1998). Especially, EPA possesses various biological effects including antioxidant, anticancer, anti-inflammatory, and vascular effects. Thus, EPA markedly alleviated valproate-induced hepatotoxicity, oxidative stress, and inflammation, while enhancing the anticonvulsant 
effects of valproate without altering its clearance (ElMowafy et al. 2011). $\beta$-Carotene showed protective effect against methotrexate and fenitrothion induced oxidative liver damage through decrease of reactive oxygen species (ROS) (Hashim and Weshahy 2002, Vardi et al. 2010). Especially Peng et al. (2013) demonstrated that low dose of $\beta$-carotene provides protection against hepatic injury. And phytosterols such as stigmasterol and campesterol were reported on their decrease effect of liver inflammation (Plat et al. 2014). Therefore, we expected the hepatic protective effect of liposoluble portion of P. yezoensis contained these bio-active components on alcohol-induced liver damage. Especially, liposoluble portion named polyunsaturated fatty acids-rich liposoluble portion due to the highest amount of polyunsaturated fatty acids and polyunsaturated fatty acids was considered as main bioactive component.
The weights and survival rates in mice were measured to evaluate the protective effect of PYLP on alcoholdamaged mice and showed in Fig. 1. It was observed that normal (= non-treatment group), alcohol only, PYLP + alcohol or silymarin + alcohol (positive control) treatments did not affect to the weights of the mice. However, alcohol critically decreased the survival rate at 3 days after treatment, whereas PYLP maintained a $100 \%$ survival rate until 8 days. At day 9, the PYLP + alcohol group showed a decrease of $20 \%$ in survival rate; however, the treatment with silymarin did not result in death of the mice at any stage during the experiments.

Table 3 showed the results of alcohol only, PYLP + alcohol, and silymarin + alcohol treatments on the levels of GOT (also known aspartate aminotransferase [AST]), GPT (also known as alanine aminotransferase [ALT]), total cholesterol and MDA in serum of mice. GOT and GPT

Table 2. Comparison of fatty acids composition in PYLP

\begin{tabular}{|c|c|c|c|c|}
\hline & Compound name & Composition (\%) & $\begin{array}{c}\text { Fatty acids } \\
\text { (g } 100 \mathrm{~g}^{-1} \text { crude lipid) }\end{array}$ & $\begin{array}{c}\text { Fatty acids } \\
\text { (g } 100 \mathrm{~g}^{-1} \text { PYLP) }\end{array}$ \\
\hline C8:0 & Octanoic acid & 0.01 & 0.01 & 0.01 \\
\hline C14:0 & Myristic acid & 1.26 & 1.07 & 1.06 \\
\hline C15:0 & Pentadecanoic acid & 1.44 & 1.21 & 1.19 \\
\hline $\mathrm{C} 16: 0$ & Palmitic acid & 21.07 & 17.81 & 17.59 \\
\hline C16:1 & Palmitoleic acid & 1.63 & 1.38 & 1.36 \\
\hline C18:0 & Stearic acid & 0.48 & 0.40 & 0.39 \\
\hline C18:1(n-9), cis & Oleic acid & 1.10 & 0.93 & 0.92 \\
\hline C18:2(n-6), cis & Linoleic acid & 4.99 & 4.22 & 4.17 \\
\hline $\mathrm{C} 18: 3(n-6)$ & Gamma-linolenic acid & 0.61 & 0.51 & 0.50 \\
\hline C20:1 & Cis-11-eicosenoic acid & 0.33 & 0.28 & 0.28 \\
\hline C18:3(n-3) & Linolenic acid & 0.34 & 0.28 & 0.28 \\
\hline $\mathrm{C} 20: 2$ & Cis-11,14-eicosadienoic acid & 0.40 & 0.34 & 0.34 \\
\hline$C 20: 3(n-6)$ & Cis-8,11,14-eicosatrienoic acid & 2.75 & 2.32 & 2.29 \\
\hline $\mathrm{C} 22: 1(\mathrm{n}-9)$ & Erucic acid & 0.32 & 0.27 & 0.27 \\
\hline C20:3(n-3) & Cis-11,14,17-eicosatrienoic acid & 0.03 & 0.03 & 0.03 \\
\hline $\mathrm{C} 20: 4(n-6)$ & Cis-5,8,11,14-eicosatetraenoic acid & 0.67 & 0.56 & 0.55 \\
\hline C23:0 & Tricosanoic acid & 6.43 & 5.43 & 5.36 \\
\hline $\mathrm{C} 22: 2$ & Cis-13,16-docosadienoic acid & 1.70 & 1.43 & 1.41 \\
\hline $\mathrm{C} 24: 0$ & Lignoceric acid & 0.35 & 0.30 & 0.30 \\
\hline C20:5(n-3) & Cis-5,8,11,14,17-eicosapentaenoic acid & 54.12 & 45.74 & 45.16 \\
\hline Total fatty acids & & 100 & 84.52 & 83.46 \\
\hline
\end{tabular}

PYLP, liposoluble portion of Pyropia yezoensis.

Table 3. Comparison of GOT, GPT, total cholesterol, and malondialdehyde in serum of mice

\begin{tabular}{lcccc}
\hline & $\begin{array}{c}\text { GOT } \\
\left(\text { karmen } \mathbf{~ m L}^{-1}\right)\end{array}$ & $\begin{array}{c}\text { GPT } \\
\left(\text { karmen } \mathbf{~ m L}^{-1}\right)\end{array}$ & $\begin{array}{c}\text { Total cholesterol } \\
\left(\mathbf{m g ~ d L}^{-1}\right)\end{array}$ & $\begin{array}{c}\text { Malondialdehyde } \\
\left(\mathbf{n m o l ~ m L}^{-1}\right)\end{array}$ \\
\hline Normal & $132.83 \pm 4.06^{\mathrm{c}}$ & $31.00 \pm 1.17^{\mathrm{c}}$ & $56.07 \pm 1.49^{\mathrm{b}}$ & $10.47 \pm 0.68^{\mathrm{c}}$ \\
Alcohol only & $193.50 \pm 10.34^{\mathrm{a}}$ & $50.75 \pm 2.53^{\mathrm{a}}$ & $76.15 \pm 5.15^{\mathrm{a}}$ & $23.06 \pm 1.15^{\mathrm{a}}$ \\
PYLP + alcohol & $158.75 \pm 6.63^{\mathrm{b}}$ & $39.13 \pm 1.45^{\mathrm{b}}$ & $59.02 \pm 1.59^{\mathrm{b}}$ & $16.60 \pm 1.34^{\mathrm{b}}$ \\
Silymarin + alcohol & $150.00 \pm 15.20^{\mathrm{bc}}$ & $37.13 \pm 1.68^{\mathrm{b}}$ & $56.84 \pm 3.00^{\mathrm{b}}$ & $15.61 \pm 0.84^{\mathrm{b}}$ \\
\hline
\end{tabular}

Values are expressed as mean \pm standard error $(n=3)$. Means with different superscripts within a column indicate significant difference $(p<0.05)$. GOT, glutamic oxaloacetic transaminase; GPT, glutamic pyruvic transaminase; PYLP, liposoluble portion of Pyropia yezoensis. 

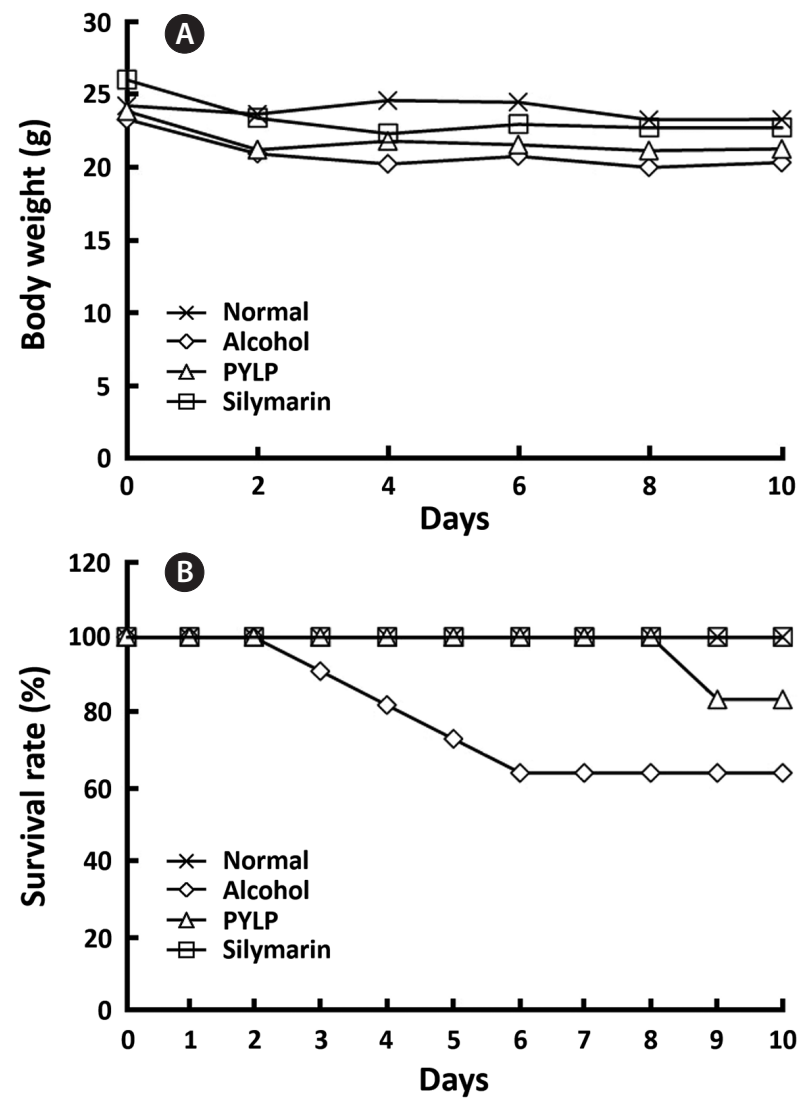

Fig. 1. Protective effect of liposoluble portion of Pyropia yezoensis (PYLP) on alcohol-induced toxicity in mice. (A) Body weight. (B) Survival rate. BALB/c mice were randomly divided into four groups as following: normal group (saline applied mice, each $100 \mu \mathrm{L}, \mathrm{n}=6$ ), alcohol only (alcohol $3 \mathrm{~g} \mathrm{~kg}^{-1}$ mice and saline co-applied mice, each $100 \mu \mathrm{L}, \mathrm{n}=10$ ), PYLP + alcohol (alcohol $3 \mathrm{~g} \mathrm{~kg}^{-1}$ mice and PYLP $25 \mathrm{mg}$ $\mathrm{kg}^{-1}$ mice co-applied mice, each $100 \mu \mathrm{L}, \mathrm{n}=10$ ), and silymarin + alcohol (alcohol $3 \mathrm{~g} \mathrm{~kg}^{-1}$ mice and silymarin $50 \mathrm{mg} \mathrm{kg}^{-1}$ mice co-applied mice, each $100 \mu \mathrm{L}, \mathrm{n}=6$ ). Alcohol, PYLP, and silymarin were daily oral administrated to mice using oral-zoned needle connected to a $1 \mathrm{~mL}$ syringe for 10 days. During the experiment period, the body weight and the survival rate of mice were daily measured.

are found in the liver, blood, heart, muscle, pancreas, and kidneys as major indicators of organ damage and liver disease (Ren et al. 2009, Lin et al. 2010). In this study, the alcohol-treated mice showed higher levels of GOT and GPT in the serum than those of the control group, whereas the treatments with PYLP as well as silymarin significantly decreased those levels. Total cholesterol in serum is a possible indicator for the protective effect of PYLP against alcoholic liver injury (Zhang et al. 2014). From the results, it was observed that total cholesterol in the serum was significantly decreased in PYLP + alcohol group, compared with the alcohol only treated group $(\mathrm{p}<0.01)$. In the previous report by Guo et al. (2007), porphyran (an acidic polysaccharide), one of the main components of the water-soluble extract of P. yezoensis, showed hepatoprotective effect against $\mathrm{CCl}_{4}$-treated mice. In the study, ALT and AST levels in the liver homogenate of porphyran $+\mathrm{CCl}_{4}$ induced mice were decreased by 11.80 and $21.70 \%$, respectively at a dose of $6.25 \mathrm{mg} \mathrm{kg}^{-1}$. The MDA level in porphyran $+\mathrm{CCl}_{4}$-induced mice decreased by $25.8 \%$. In recent, Choi et al. (2016) reported that glycoproteins from P.yezoensis (PYGP) protect chronic ethanol-induced hepatotoxicity in rats. As the study, PYGP showed the significant hepatoprotective effect by decreasing both GOT and GTP, and increasing the activations of GSH, GSH-px, and catalase in $300 \mathrm{mg} \mathrm{kg}^{-1}$ of rat. From the results, PYLP might be considered to be a useful hepatoprotective agent.

Chronic ethanol exposure impairs endogenous nonenzymatic (e.g., GSH) and enzymatic (e.g., superoxide dismutase [SOD] and GPx) antioxidant systems that protect hepatocytes against oxidative damage (Cao et al. 2015). Thus, a large amounts of ROS generated by ethanol stimulate the peroxidation of low-density lipoprotein cholesterol which causes a significant increase in MDA formation. Therefore, MDA is often used as an indicator of oxidative status (Harris et al. 2015, Macan et al. 2015). As shown in Fig. 2A-C, there were significant reductions in the activations of the enzymes in livers of the mice administered with alcohol, whereas PYLP significantly increased them $(\mathrm{p}<0.01)$. And the alcohol treatment also significantly increased the level of TBARS, whereas PYLP inhibited the cholesterol peroxidation in alcohol treated mice (Fig. 2D). Silymarin and PYLP exhibited a similar protective effect against alcohol-induced oxidative stress.

Generally, alcohol has an adverse effect on liver tissues (Matsumoto et al. 2016); therefore, a histopathological change in liver tissue is key in evaluating the protective effect of PYLP against alcohol-induced liver injury. As shown in Fig. 3, livers of the normal mice showed a normal architecture of the hepatic cells, bile lobes, and periportal regions. The hepatic tissues from the alcohol only groups showed hepatocyte degeneration manifested by vacuolization and hemorrhagic lesions. However, the liver tissues from the silymarin and alcohol co-administered groups were less damaged with hepatic degeneration. In addition, the PYLP-treated group also showed intact liver histology with no damaged hepatocytes and portal vasculature, unlike the alcohol only group.

Oxidative stress induced by ethanol or other stimuli generates apoptosis via expression of p53 and Bcl-2 family proteins (Liu et al. 2008, Behera et al. 2014, Chen et al. 2016). PYLP decreased the expression of the pro- 

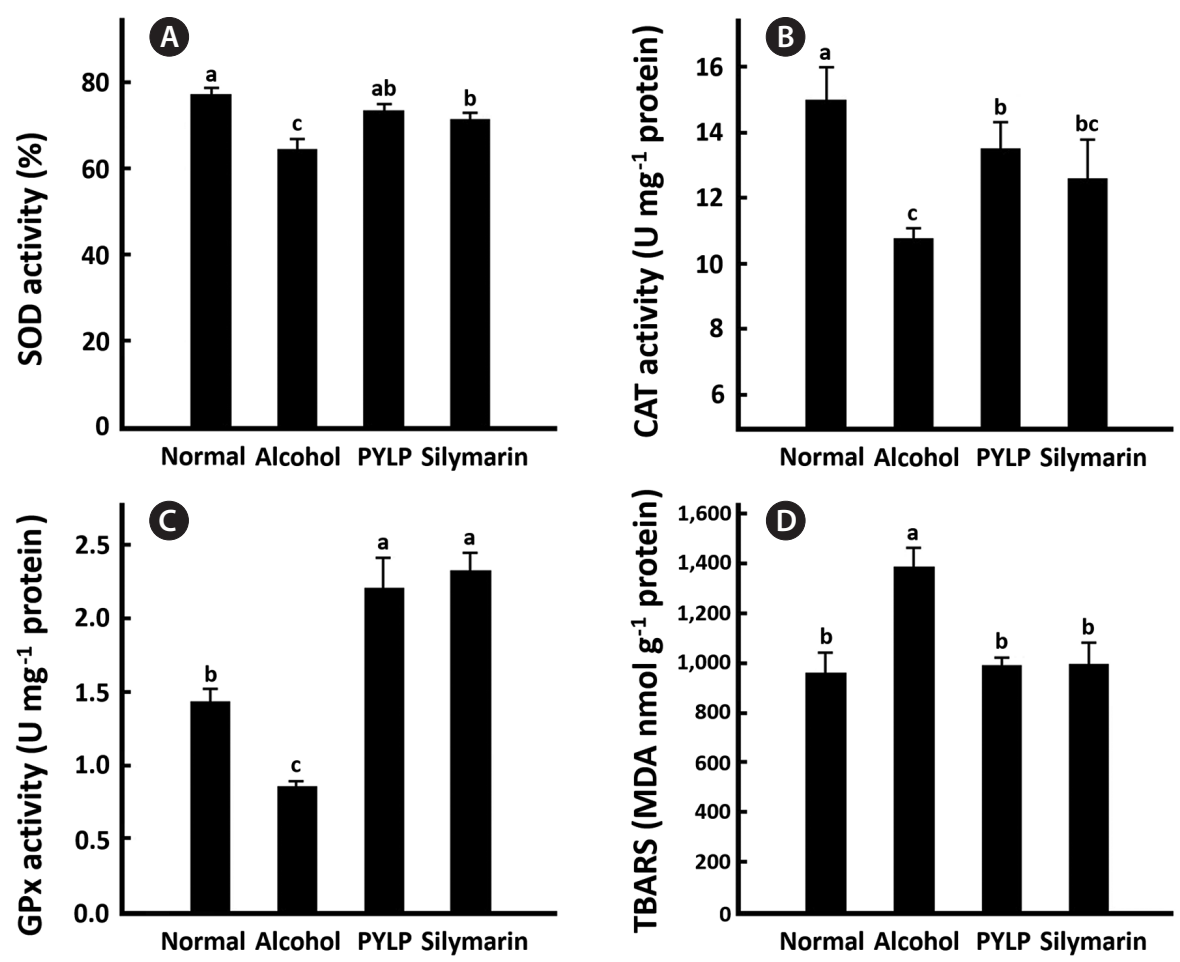

Fig. 2. Protective effect of liposoluble portion of Pyropia yezoensis (PYLP) on alcohol-induced oxidative stress in liver. (A) Superoxide dismutase (SOD) activity. (B) Catalase (CAT) activity. (C) Glutathione peroxidase (GPx) activity. (D) Thiobarbituric acid reactive substances (TBARS) (malondialdehyde [MDA]). Each experiment was performed in four groups as follows: normal (= non-treatment), alcohol only, PYLP + alcohol, and silymarin + alcohol (positive control) treatments. Data are expressed as mean \pm standard error $(n=3)$. Different letters indicate significant differences $(p<$ 0.05 ) according to Duncan test.
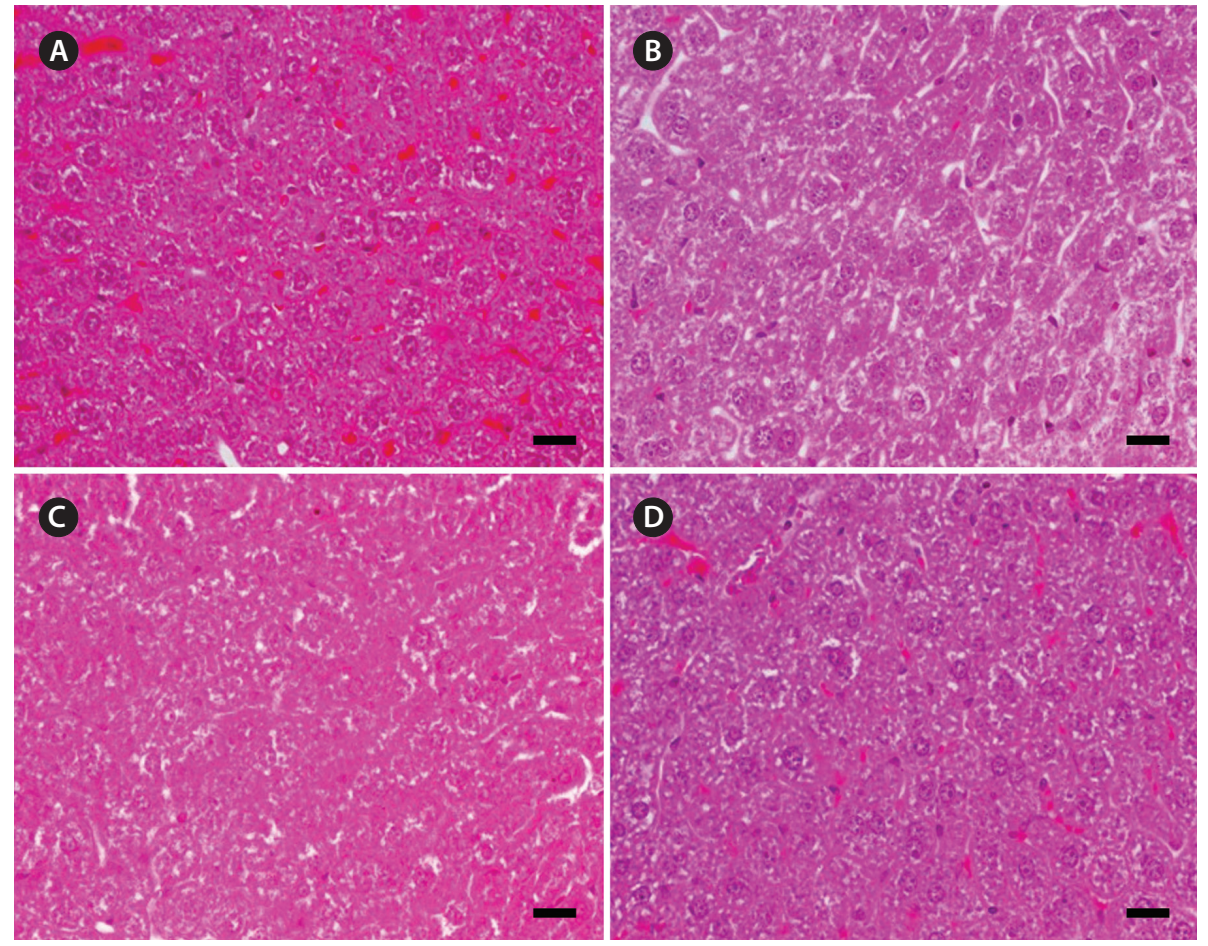

Fig. 3. Histologic results of tissues in alcohol-induced mice. The liver tissue sections were stained with hematoxylin and eosin (H\&E staining, $\times 100$ ). (A) Normal group (non-treatment). (B) Alcoholic group (EtOH). (C) Alcoholic plus liposoluble portion of Pyropia yezoensis group. (D) Alcoholic plus silymarin group. Scale bars represent: A-D, $10 \mu \mathrm{m}$. 
A
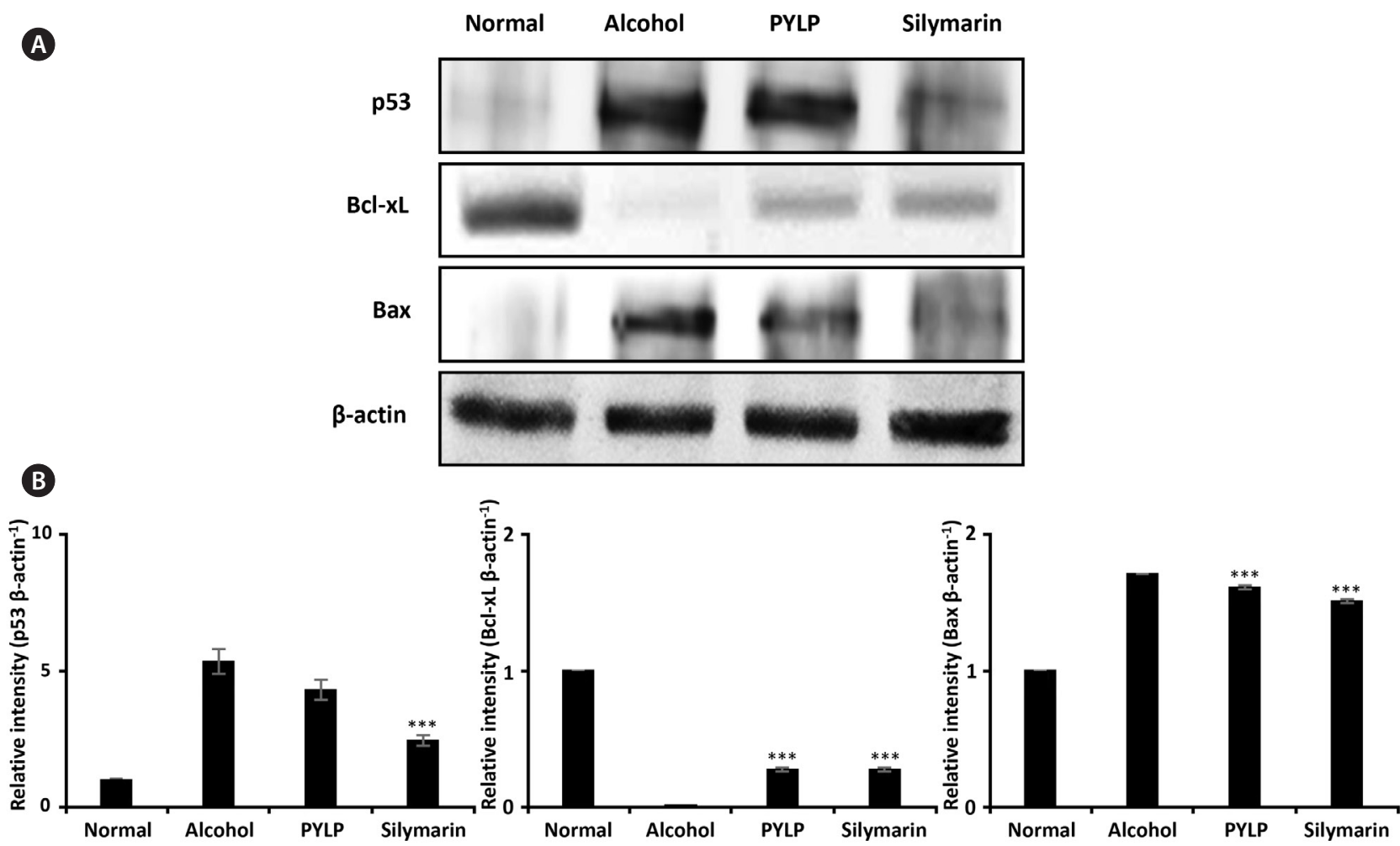

Fig. 4. Liposoluble portion of Pyropia yezoensis (PYLP) reduced apoptosis generated in liver by alcohol-induced oxidative stress. Densitometry analysis (A) and relative intensity (B) of p53, Bcl-xL, and Bax compared to $\beta$-actin. Each experiment was performed in four groups as follows: normal (= non-treatment), alcohol only, PYLP + alcohol, and silymarin + alcohol (positive control) treatments. Values are expressed as mean \pm standard deviation. Statistical analysis was carried out with the Tukey's test (***p $<0.005)$.

apoptotic proteins, p53 and Bax, whereas increased the expression of anti-apoptotic protein, Bcl-xL. The results shown in Fig. 4 indicate that ethanol increased the expression of the pro-apoptotic protein, p53, and Bax proteins, while PYLP decreased the expression of p53 and Bax, and increased the expression of anti-apoptotic protein and Bcl-xL. However, PYLP showed a relatively lower anti-apoptotic effect than silymarin. The expression of anti-apoptotic protein, Bcl-xL was slightly elevated in the PYLP-treated mice than in the alcohol only group. Collectively, PYLP inhibited apoptosis of hepatocytes via activation of p53 and Bax in the mice administered alcohol.

\section{CONCLUSION}

Alcohol occurs liver injury by various mechanisms, such as oxidative stress and apoptosis signaling pathway. Our results indicate that PYLP reduces alcohol-induced liver injury in vivo by reducing total cholesterol, inhibit- ing ROS generation, increasing activities of antioxidant enzyme, reducing MDA formation and anti-apoptosis pathway. These effects are due to the abundant functional components of PYLP such as the polyunsaturated fatty acids. Finally, this study suggests that PYLP is more beneficial to human health for protecting alcohol-damaged liver injury.

\section{ACKNOWLEDGEMENTS}

This research was supported by Ministry of Agriculture, Food and Rural Affairs (MAFRA), Ministry of Oceans and Fisheries (MOF), Rural Development Administration (RDA) and Korea Forest Service (KFS) (21300404-2-SB930), and this work was also supported by Korea Health Technology R\&D Project through the Korea Health Industry Development Institute (KHIDI) funded by the Ministry for Health and Welfare, Korea (HI14C1135 \& HI15C0987). 


\section{CONFLICTS OF INTEREST}

The authors declare that they have no potential conflicts of interest.

\section{REFERENCES}

Ahamad, M. N., Saleemullah, M., Shah, H. U., Khalil, I. A. \& Saljoqi, A. U. R. 2007. Determination of beta carotene content in fresh vegetables using high performance liquid chromatography. Sarhad. J. Agric. 23:767-770.

Allain, C. C., Poon, L. S., Chan, C. S. G., Richmond, W. \& Fu, P. C. 1974. Enzymatic determination of total serum cholesterol. Clin. Chem. 20:470-475.

Asanka Sanjeewa, K. K., Fernando, I. P. S., Kim, S. -Y., Kim, W. -S., Ahn, G., Jee, Y. \& Jeon, Y. -J. 2019. Ecklonia cava (Laminariales) and Sargassum horneri (Fucales) synergistically inhibit the lipopolysaccharide-induced inflammation via blocking NF- $\mathrm{B}$ and MAPK pathways. Algae 34:45-56.

Behera, B., Mishra, D., Roy, B., Devi, K. S. P., Narayan, R., Das, J., Ghosh, S. K. \& Maiti, T. K. 2014. Abrus precatorius agglutinin-derived peptides induce ROS-dependent mitochondrial apoptosis through JNK and Akt/P38/P53 pathways in HeLa cells. Chem-Biol. Interact. 222:97105.

Bradford, M. M. 1976. A rapid and sensitive method for the quantitation of microgram quantities of protein utilizing the principle of protein-dye binding. Anal. Biochem. 72:248-254.

Burdge, G. C. 1998. The role of docosahexaenoic acid in brain development and fetal alcohol syndrome. Biochem. Soc. Trans. 26:246-252.

Cao, Y. -W., Jiang, Y., Zhang, D. -Y., Zhang, X. -J., Hu, Y. -J., Li, P., Su, H. \& Wan, J. -B. 2015. The hepatoprotective effect of aqueous extracts of Penthorum chinense Pursh against acute alcohol-induced liver injury is associated with ameliorating hepatic steatosis and reducing oxidative stress. Food Funct. 6:1510-1517.

Chen, L. -Y., Chen, Q., Cheng, Y. -F., Jin, H. -H., Kong, D. -S., Zhang, F., Wu, L., Shao, J. -J. \& Zheng, S. -Z. 2016. Dallyl trisulfide attenuates ethanol-induced hepatic steatosis by inhibiting oxidative stress and apoptosis. Biomed. Pharmacother. 79:35-43.

Choi, J. -W., Kim, I. -H., Kim, Y. -M., Lee, M. -K., Choi, Y. -H. \& Nam, T. -J. 2016. Protective effect of Pyropia yezoensis glycoprotein on chronic ethanol consumption-induced hepatotoxicity in rats. Mol. Med. Rep. 14:4881-4886.

Dai, Y. -L., Kim, G. H., Kang, M. -C. \& Jeon, Y. -J. 2020. Protec- tive effects of extracts from six local strains of Pyropia yezoensis against oxidative damage in vitro and in zebrafish model. Algae 35:189-200.

Ding, Y., Kim, S. H., Lee, J. J., Hong, J. T., Kim, E. -A., Kang, D. -H., Heo, S. -J. \& Lee, S. -H. 2019. Anti-melanogenesis activity of Ecklonia cava extract cultured in tanks with magma seawater of Jeju Island. Algae 34:177-185.

El-Mowafy, A. M., Abdel-Dayem, M. A., Abdel-Aziz, A., ElAzab, M. F. \& Said, S. A. 2011. Eicosapentaenoic acid ablates valproate-induced liver oxidative stress and cellular derangement without altering its clearance rate: dynamic synergy and therapeutic utility. Biochim. Biophys. Acta 1811:460-467.

Guo, T. -T., Xu, H. -L., Zhang, L. -X., Zhang, J. -P., Guo, Y. -F., $\mathrm{Gu}$, J. -W. \& He, P. -M. 2007. In vivo protective effect of Porphyra yezoensis polysaccharide against carbon tetrachloride induced hepatotoxicity in mice. Regul. Toxicol. Pharmacol. 49:101-106.

Harris, P. S., Roy, S. R., Coughlan, C., Orlicky, D. J., Liang, Y., Shearn, C. T., Roede, J. R. \& Fritz, K. S. 2015. Chronic ethanol consumption induces mitochondrial protein acetylation and oxidative stress in the kidney. Redox Biol. 6:33-40.

Hashim, E. F. \&Weshahy, K. 2002. Analytical and microscopical studies on the protective effect of ascorbic acid (vitamin C) and beta-carotene against the toxicity induced by fenitrothion on the liver of female albino rats. Egypt. J. Hosp. Med. 7:1-27.

Isaka, S., Cho, K., Nakazono, S., Abu, R., Ueno, M., Kim, D. \& Oda, T. 2015. Antioxidant and anti-inflammatory activities of porphyrin isolated from discolored nori (Porphyra yezoensis). Int. J. Biol. Macromol. 74:68-75.

Kazłowska, K., Lin, H. -T. V., Chang, S. -H. \& Tsai, G. -J. 2013. In vitro and in vivo anticancer effects of sterol fraction from red algae Porphyra dentata. Evid-Based. Complement. Alternat. Med. 2013:493869.

Kim, H. -H., Kim, H. -S., Ko, J. -Y., Kim, C. -Y., Lee, J. -H. \& Jeon, Y. -J. 2016. A single-step isolation of useful antioxidant compounds from Ishige okamurae by using centrifugal partition chromatography. Fish. Aquat. Sci. 19:22.

Kim, S., You, D. H., Han, T. \& Choi, E. -M. 2014. Modulation of viability and apoptosis of UVB-exposed human keratinocyte HaCaT cells by aqueous methanol extract of laver (Porphyra yezoensis). J. Photochem. Photobiol. B 141:301-307.

Lambert, J. C., Zhou, Z., Wang, L., Song, Z., Mcclain, C. J. \& Kang, Y. J. 2003. Prevention of alterations in intestinal permeability is involved in zinc inhibition of acute ethanol-induced liver damage in mice. J. Pharmacol. Exp. 
Ther. 305:880-886.

Lee, J. -H., Ko, J. -Y., Oh, J. -Y., Kim, C. -Y., Lee, H. -J., Kim, J. \& Jeon, Y. -J. 2014. Preparative isolation and purification of phlorotannins from Ecklonia cava using centrifugal partition chromatography by one-step. Food. Chem. 158:433-437.

Lee, J. -H., Ko, J. -Y., Samarakoon, K., Oh, J. -Y., Heo, S. -J., Kim, C. -Y., Nah, J. -W., Jang, M. -K., Lee, J. -S. \& Jeon, Y. -J. 2013. Preparative isolation of sargachromanol E from Sargassum siliquastrum by centrifugal partition chromatography and its anti-inflammatory activity. Food. Chem. Toxicol. 62:54-60.

Lee, S. M., Kim, N. -H., Ji, Y. K., Kim, Y. N., Jeon, Y. -J., Heo, J. D., Jeong, E. J. \& Rho, J. -R. 2020. Sulfoquinovosylmonoacylglycerols regulating intestinal inflammation in coculture system from the brown alga Turbinaria ornata. Algae 35:201-212.

Lemaitre, R. N., King, I. B., Mozaffarian, D., Kuller, L. H., Tracy, R. P. \& Siscovick, D. S. 2003. n-3 polyunsaturated fatty acids, fatal ischemic heart disease, and nonfatal myocardial infarction in older adults: the cardiovascular health study. Am. J. Clin. Nutr. 77:319-325.

Lin, J. -D., Lin, P. -Y., Chen, L. -M., Fang, W. -H., Lin, L. -P. \& Loh, C. -H. 2010. Serum glutamic-oxaloacetic transaminase (GOT) and glutamic-pyruvic transaminase (GPT) levels in children and adolescents with intellectual disabilities. Res. Dev. Disabil. 31:172-177.

Lin, X., Zhang, S., Huang, R., Wei, L., Tan, S., Liang, S., Tian, Y., Wu, X., Lu, Z. \& Huang, Q. 2014. Helenalin attenuates alcohol-induced hepatic fibrosis by enhancing ethanol metabolism, inhibiting oxidative stress and suppressing HSC activation. Fitoterapia 95:203-213.

Liu, B., Chen, Y. \& Clair, D. K. S. 2008. ROS and p53: a versatile partnership. Free. Radic. Biol. Med. 44:1529-1535.

Lluís, L., Taltavull, N., Muñoz-Cortés, M., Sánchez-Martos, V., Romeu, M., Giralt, M., Molinar-Toribio, E., Torres, J. L., Pérez-Jiménez, J., Pazos, M., Méndez, L., Gallardo, J. M., Medina, I. \& Nogués, M. R. 2013. Protective effect of the omega-3 polyunsaturated fatty acids: eicosapentaenoic acid/docosahexaenoic acid 1:1 ratio on cardiovascular disease risk markers in rats. Lipids Health Dis. 12:140.

Lu, C., Xu, W., Zhang, F., Jin, H., Chen, Q., Chen, L., Shao, J., Wu, L., Lu, Y. \& Zheng, S. 2015. Ligustrazine prevents alcohol-induced liver injury by attenuating hepatic steatosis and oxidative stress. Int. Immunopharmacol. 29:613-621.

Macan, M., Vukšić, A., Žunec, S., Konjevoda, P., Lovrić, J., Kelava, M., Štambuk, N., Vrkić, N. \& Bradamante, V. 2015. Effects of simvastatin on malondialdehyde level and esterase activity in plasma and tissue of normolip- idemic rats. Pharmacol. Rep. 67:907-913.

Matsumoto, A., Thompson, D., Chen, Y., Vasiliou, V., Kawamoto, T. \& Ichiba, M. 2016. Heme oxygenase 1 protects ethanol-administered liver tissue in Aldh2 knockout mice. Alcohol 52:49-54.

Ohkawa, H., Ohishi, N. \& Yagi, K. 1979. Assay for lipid peroxides in animal tissues by thiobarbituric acid reaction. Anal. Biochem. 95:351-358.

Parrish, C. C. 2009. Essential fatty acids in aquatic food webs. In Arts, M. T., Brett, M. T. \& Kainz, M. J. (Eds.) Lipids in Aquatic Ecosystems. Springer, New York, NY, pp. 309-326.

Peng, H. -C., Chen, Y. -L., Yang, S. -Y., Ho, P. -Y., Yang, S. -S., Hu, J. -T. \& Yang, S. -C. 2013. The antiapoptotic effects of different doses of $\beta$-carotene in chronic ethanol-fed rats. Hepatobiliary Surg. Nutr. 2:132-141.

Plat, J., Hendrikx, T., Bieghs, V., Jeurissen, M. L. J., Walenbergh, S. M. A., van Gorp, P. J., De Smet, E., Konings, M., Vreugdenhil, A. C. E., Guichot, Y. D., Rensen, S. S., Buurman, W. A., Greve, J. W. M., Lütjohann, D., Mensink, R. P. \& Shiri-Sverdlov, R. 2014. Protective role of plant sterol and stanol esters in liver inflammation: insights from mice and humans. PLoS ONE 9:e110758.

Reitman, S. \& Frankel, S. 1957. A colorimetric method for the determination of serum glutamic oxalacetic and glutamic pyruvic transaminases. Am. J. Clin. Pathol. 28:56-63.

Ren, H. -X., Huang, X. -J., Kim, J. -H., Choi, Y. -K. \& Gu, N. 2009. Pt/Au bimetallic hierarchical structure with micro/nano-array via photolithography and electrochemical synthesis: from design to GOT and GPT biosensors. Talanta 78:1371-1377.

Ruxton, C. H. S., Reed, S. C., Simpson, M. J. A. \& Millington, K. J. 2004. The health benefits of omega-3 polyunsaturated fatty acids: a review of the evidence. J. Hum. Nutr. Diet. 17:449-459.

Sánchez-Machado, D. I., López-Hernández, J., Paseiro-Losada, P. \& López-Cervantes, J. 2004. An HPLC method for the quantification of sterols in edible seaweeds. Biomed. Chromatogr. 18:183-190.

Santos Rocha, S. W., Silva, B. S., Gomes, F. O. S., Soares e Silva, A. K., Raposo, C., Barbosa, K. P. S., Torres, D. O. C., dos Santos, A. C. O. \& Peixoto, C. A. 2012. Effect of diethylcarbamazine on chronic hepatic inflammation induced by alcohol in C57BL/6 mice. Eur. J. Pharmacol. 689:194-203.

Shanura Fernando, I. P., Asanka Sanjeewa, K. K., Samarakoon, K. W., Lee, W. W., Kim, H. -S., Kang, N., Ranasinghe, P., Lee, H. -S. \& Jeon, Y. -J. 2017. A fucoidan fraction purified from Chnoospora minima: a potential inhibi- 
tor of LPS-induced inflammatory responses. Int. J. Biol. Macromol. 104:1185-1193.

Shin, D. -M., An, S. -R., In, S. -K. \& Koo, J. -G. 2013. Seasonal variation in the dietary fiber, amino acid and fatty acid contents of Porphyra yezoensis. Korean J. Fish. Aquat. Sci. 46:337-342.

Suresh, V. \& Asha, V. V. 2008. Preventive effect of ethanol extract of Phyllanthus rheedii Wight. On D-galactosamine induced hepatic damage in Wistar rats. J. Ethnopharmacol. 116:447-453.

Uauy, R. \& Valenzuela, A. 2000. Marine oils: the health benefits of n-3 fatty acids. Nutrition 16:680-684.

Vardi, N., Parlakpinar, H., Cetin, A., Erdogan, A. \& Ozturk, I. C. 2010. Protective effect of $\beta$-carotene on methotrexate-induced oxidative liver damage. Toxicol. Pathol. 38:592-597.
Yokoyama, M., Origasa, H., Matsuzaki, M., Matsuzawa, Y., Saito, Y., Ishikawa, Y., Oikawa, S., Sasaki, J., Hishida, H., Itakura, H., Kita, T., Kitabatake, A., Nakaya, N., Sakata, T., Shimada, K., Shirato, K. \& Japan EPA lipid intervention study (JELIS) Investigators. 2007. Effects of eicosapentaenoic acid on major coronary events in hypercholesterolaemic patients (JELIS): a randomized open-label, blinded endpoint analysis. Lancet 369:1090-1098.

Zang, F., Qin, S., Ma, C., Li, W. \& Lin, J. 2020. Structure, function and applications of phycoerythrin: a unique light harvesting protein in algae. Chin. Sci. Bull. 65:565-576.

Zhang, P., Ma, D., Wang, Y., Zhang, M., Qiang, X., Liao, M., Liu, X., Wu, H. \& Zhang, Y. 2014. Berberine protects liver from ethanol-induced oxidative stress and steatosis in mice. Food Chem. Toxicol. 74:225-232. 